\title{
A FATAL CASE OF BILATERAL INTERSTITIAL PNEUMONIA (BLIP): INTERFERON ALPHA 2 A INDUCED
}

\author{
BALAJI 0 ${ }^{1}$, BAIRY KL ${ }^{1 *}$, AMITA PRIYA ${ }^{1}{ }^{1}$, JOSEPH THOMAS ${ }^{2}$, NAVIN PATIL ${ }^{1}$
}

${ }^{1}$ Department of Pharmacology, Kasturba Medical College, Manipal University, Manipal, Karnataka, India. ${ }^{2}$ Department of Medical Oncology, Kasturba Medical College, Manipal University, Manipal, Karnataka, India. Email: navin903@gmail.com

Received: 13 April 2017, Revised and Accepted: 07 July 2017

\section{ABSTRACT}

Adult T-cell leukemia/lymphoma (ATLL) is a rare lymph proliferative disorder of mature CD4 T-cells caused by the human T-lymph tropic type 1 (HTLV 1) of retrovirus family. Combination of zidovudine and interferon Alfa combination is one of most commonly used regimen. Many drugs are implicated in causing interstitial lung disease. Hence, we report a case of interferon Alfa-induced bilateral interstitial pneumonia in a 32-year-old female patient diagnosed with ATLL with HTLV 1 positivity.

Keywords: Pneumonia, Interferon, Zidovudine, Adult T-cell leukemia.

(C) 2017 The Authors. Published by Innovare Academic Sciences Pvt Ltd. This is an open access article under the CC BY license (http://creativecommons. org/licenses/by/4. 0/) DOI: http://dx.doi.org/10.22159/ajpcr.2017.v10i10.19131

\section{INTRODUCTION}

Adult T-cell leukemia/lymphoma (ATLL) is a rare lymph proliferative disorder of mature CD4 T-cells caused by the human T-lymph trophic type 1 (HTLV) of retrovirus family first recognized in 1977 in Kyoto, Japan by Uchiyama et al. [1]. Various chemotherapy regimens are used in the treatment of this condition. Combination of zidovudine and interferon Alfa combination is one of most commonly used because of higher response rates and durability [2]. Many drugs are implicated in causing interstitial lung disease and bronchiolitis obliterans organizing pneumonia (BOOP) [3]. Global incidence of drug-induced interstitial lung disease ranges from $2.5 \%$ to $3 \%$ [4]. Hence, we report a case of interferon Alfa-induced bilateral interstitial pneumonia in a 32-yearold female patient diagnosed with ATLL with HTLV 1 positivity.

\section{CASE REPORT}

Informed consent was taken from the patient. A 32-year-old female patient presented with fatigue, weakness, and left shoulder pain. There was no pallor, edema, icterus, cyanosis, clubbing, and associated weight loss with a negative history of blood loss, no loss of appetite. On examination splenomegaly, cervical/axillary lymphadenopathy was noted. Family history was insignificant. The patient was not a smoker/alcoholic. The patient was readmitted 10 days later with c/o of popular eruptions all over the body. Chest X-ray was normal (Fig. 1). Liver and renal function tests were normal. Coagulation profile was normal. Blood counts were normal except for elevation of total leukocyte count. Peripheral smear showed features suggestive of hematological malignancy. 84\% abnormal lymphocytes were noted on bone marrow aspirate suggestive of ATLL. It was confirmed with flow cytometry which showed CD3, CD4, CD5, and CD25 positivity. Biopsy of lymph nodes finally confirmed ATLL. Skin biopsy showed lymphoid cells. Antibodies to HIV 1, HIV 2, HCV, HBV was non-reactive. HTLV 1 serology was positive. The patient was started on zidovudine $1 \mathrm{~g}$ daily and interferon alpha 2A, 9 million units s.c once daily. After 7 days' patient complaint of dyspnea, dry cough, 02 saturation $84 \%$. X-ray revealed acute respiratory distress syndrome (ARDS) (Fig. 2). There was no fever and sputum production. After 10 days, bilateral interstitial pneumonia (IP) developed and CT scan confirmed it (Fig. 3). Interferon was suspected to be the causal agent and was discontinued. Mechanical ventilation of non invasive form was given and patient was maintained on bi- level positive BIPAP positive airway pressure. Patient condition did not improve and there was a difficulty in weaning of ventilator.
Oxygen saturation did not improve and there was cardiac arrest twice and successful resuscitation was done to save the life of patient. Patient expired on third arrest.

\section{DISCUSSION}

ATLL is a rare lymph proliferative disorder of mature CD4 T-cells caused by the HTLV of retrovirus family first recognized in 1977 in Kyoto, Japan by Uchiyama et al. [1]. It is transmitted from individual to individual mainly through sexual contact, blood transfusions, sharing of intravenous needles, and through breast milk from carrier mother-tonew born through breast milk. India being a non-endemic region only few case reports are reported with recent upsurge in southern parts of India [5]. The prevalence of HTLV 1 in HIV negative individuals is only $0.3 \%$ in India and so far, only nine cases have been reported from India [5]. Zidovudine with interferon Alfa is one of the most widely used combination in the treatment of ATLL caused by HTLV 1 infections and studies have noted increased durability and higher response rates with this combination [6]. Zidovudine main mechanism is terminating DNA replication by its cytostatic effects and blocks the transformation of normal peripheral-blood lymphocytes [6]. Interferon Alfa acts by inhibition of protein synthesis and hence cell growth. It also inhibits the expression of major histocompatibility complex 1 and 2 [7]. When used in combination it is also thought to enhance the action of zidovudine. Major toxicities include hepatic and hematological toxicity.

Many drugs are implicated in causing interstitial lung disease and global incidence of drug-induced interstitial lung disease ranges from $2.5 \%$ to $3 \%$ [4]. Many studies states that it is usually underreported and hence frequency is unknown. Many anti-inflammatory, antimicrobials, anticancer drugs, biologicals, and cardiovascular drugs have been implemented to cause interstitial lung disease, and interferon is also one among them [8]. Incidence of interferon causing IP ranges from $0.01 \%$ to $0.3 \%$ globally [9] and the spectrum of pulmonary toxicities ranges from pulmonary sarcoidosis, IP, BOOP, pleural effusion, and exacerbation of bronchial asthma to ARDS [10]. Postulated mechanism by which interferon causes lung tissue fibrosis is by inhibiting suppressor T-cells, increasing cytotoxic T-cells [11]. It is also said to induce proinflammatory cytokines and cause excess release of fibrinogenic cytokines [11].

In our case, patient was started on zidovudine and interferon combination and on $7^{\text {th }}$ day he complained of dyspnea and ARDS was 


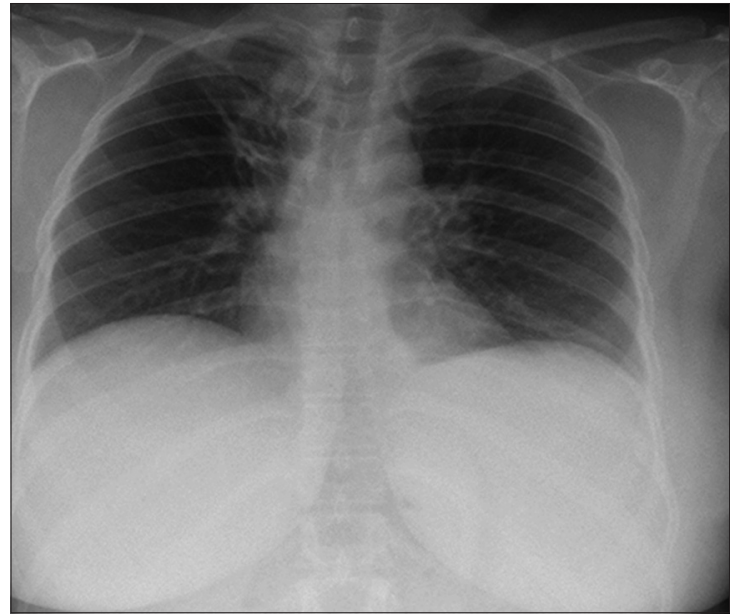

Fig. 1: Before interferon therapy - normal X-ray

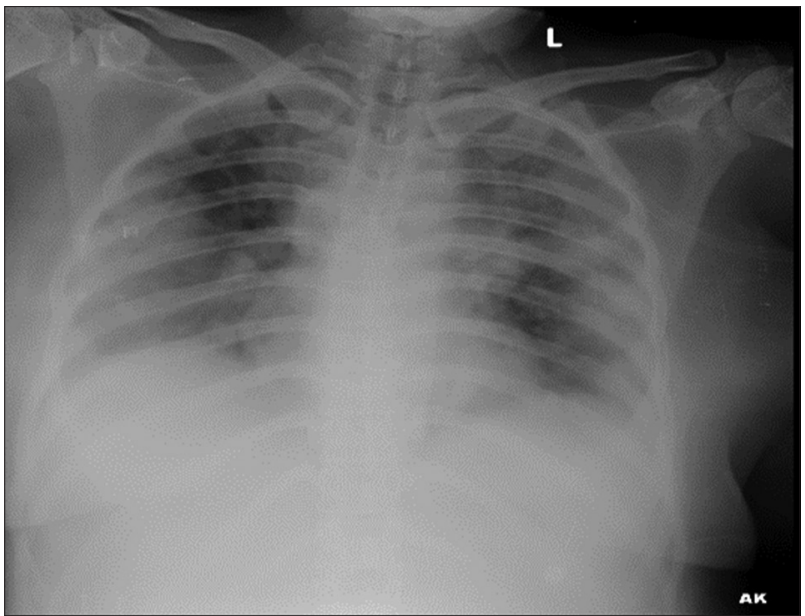

Fig. 2: Development of acute respiratory distress syndrome with signs of interstital pneumonia after interferon therapy

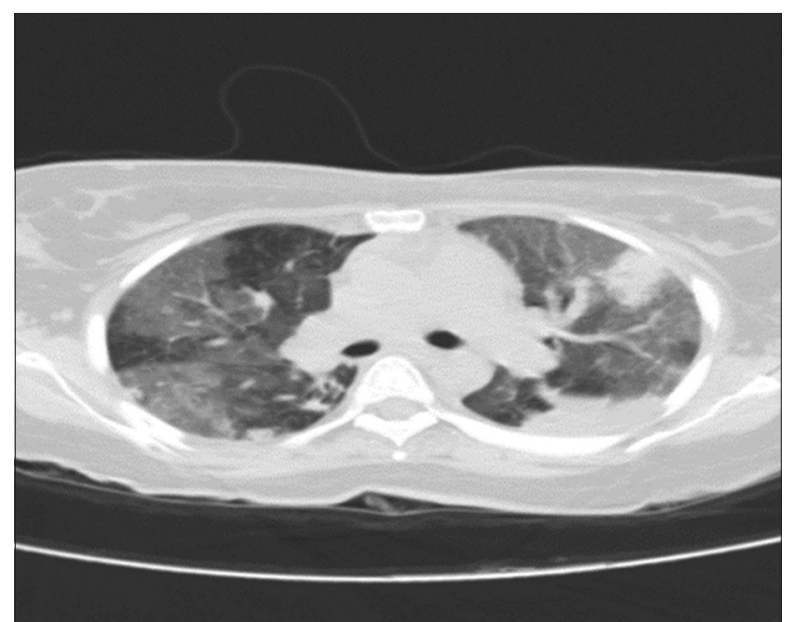

Fig. 3: Computed tomography chest showing bilateral interstitial pneumoni

suspected and X-ray chest confirmed presence of ground glass opacities and contrast-enhanced computed tomography was taken, as it is the gold standard in diagnosing IP and it confirmed the presence of bilateral IP with ground glass opacification. Immediately drug was stopped, and antibiotic was given and patient was put on non-invasive ventilation. He was put on BiPAP for maintenance, but patient condition did not improve and $\mathrm{SpO}_{2}$ kept deteriorating. Patient had 2 cardiac arrests and was resuscitated successfully but expired following third arrest.

Hence, causality assessment using Naranjo scale [12] was done and a probable causal relationship was established. Adverse drug event was found be highly severe and not preventable as per Hartwig's severity and Thornton's preventability scaling, respectively $[13,14]$.

\section{CONCLUSION}

Incidence of drug-induced IP is very low and since interferon is main stay in the treatment of ATLL along with zidovudine proper care must be taken to avoid lung complications as we report here a death due to interferon Alfa. Serial chest X-ray monitoring is required during treatment and drug should be withdrawn immediately if sign of pulmonary disease develop. Hence, adverse drug monitoring studies are necessary, and clinical prospective studies can be undertaken.

\section{REFERENCES}

1. Uchiyama T, Yodoi J, Sagawa K, Takatsuki K, Uchino H. Adult T-cell leukemia: Clinical and hematologic features of 16 cases. Blood 1977;50(3):481-92.

2. Gill PS, Harrington W Jr, Kaplan MH, Ribeiro RC, Bennett JM, Liebman HA, et al. Treatment of adult T-cell leukemia-lymphoma with a combination of interferon alfa and zidovudine. N Engl J Med 1995;332(26):1744-8.

3. Paul AM, Antony A, Sruti NU, Bameed H. A case report on ayurvedic medicine (red mercuric sulphate) induced bronchiolitis obliterans organizing pneumonia (boop) in sero positive rheumatoid patient. Int J Pharm Pharm Sci 2015;7(11):399-401.

4. Coultas DB, Zumwalt RE, Black WC, Sobonya RE. The epidemiology of interstitial lung diseases. Am J Respir Crit Care Med 1994;150(4):967-72.

5. Khader A, Shaan M, Balakrishnan S, Ambooken B, Muhammed K, Rajan U. Multifaceted adult T-cell leukemia/lymphoma in India: A case series. Indian J Dermatol 2015;60(1):103.

6. Furman PA, Fyfe JA, St Clair MH, Weinhold K, Rideout JL, Freeman GA, et al. Phosphorylation of 3'-azido-3'-deoxythymidine and selective interaction of the 5'-triphosphate with human immunodeficiency virus reverse transcriptase. Proc Natl Acad Sci U S A 1986;83(21):8333-7.

7. Friedman RL, Manly SP, McMahon M, Kerr IM, Stark GR. Transcriptional and posttranscriptional regulation of interferon-induced gene expression in human cells. Cell 1984;38(3):745-55.

8. Schwaiblmair M, Behr W, Haeckel T, Märkl B, Foerg W, Berghaus T. Drug induced interstitial lung disease. Open Respir Med J 2012;6:63-74.

9. Solsky J, Liu J, Peng M, Schaerer M, Tietz A. Rate of interstitial pneumonitis among hepatitis virus $\mathrm{C}$-infected patients treated with pegylated interferon. J Hepatol 2009;50 Suppl 1:S238.

10. Kumar KS, Russo MW, Borczuk AC, Brown M, Esposito SP, Lobritto SJ, et al. Significant pulmonary toxicity associated with interferon and ribavirin therapy for hepatitis C. Am J Gastroenterol 2002;97(9):2432-40.

11. Tilg H. New insights into the mechanisms of interferon alfa: An immunoregulatory and anti-inflammatory cytokine. Gastroenterology 1997;112(3):1017-21.

12. Naranjo CA, Busto U, Sellers EM, Sandor P, Ruiz I, Roberts EA, et al. A method for estimating the probability of adverse drug reactions. Clin Pharmacol Ther 1981;30(2):239-45.

13. Raut A, Pawar A, Pankaj M, Srivastava P, Mishra A. Clinical pattern and severity of cutaneous adverse drug reactions. Int J Pharm Pharm Sci 2013;5(2):612-6.

14. Schumock GT, Thornton JP. Focusing on the preventability of adverse drug reactions. Hosp Pharm 1992;27(6):538. 